\title{
Manuel Alcántara Sáez: Un cientista social que no puede estar ajeno a los cambios ${ }^{1}$

\author{
Graciela Carrazco López*
}

Manuel Alcántara Sáez es actualmente uno de los latinoamericanistas europeos más importantes. Académico de la Universidad de Salamanca; doctor en Ciencias Políticas (1984) y licenciado en Ciencias Políticas y Sociología (1976) por la Universidad Complutense de Madrid. Su área de investigación son las élites políticas, con líneas de trabajo en los partidos políticos, en los poderes legislativos, en comportamiento electoral y en opinión pública en América Latina.

Ha recibido el Doctorado Honoris Causa por la Universidad de San Martín en Argentina y la Orden de Bernardo O'Higgins por el Gobierno de Chile. Como especialista en América Latina ha sido invitado en Instituciones de Educación Superior como la Universidad de Carolina del Norte, la Universidad de Notre Dame, la Universidad Tulane y el Instituto de Estudios Políticos de París, entre otras.

Entre sus principales publicaciones se encuentran El oficio de politico (2012); ¿Instituciones o máquinas ideológicas? Origen, programa y organización de los partidos politicos latinoamericanos (2004); Sistemas politicos de América Latina (1999 y varias ediciones posteriores) y Gobernabilidad, crisis y cambio (1994); entre otros.

\footnotetext{
* Estudiante del Programa de Doctorado en Pedagogía, Facultad de Estudios Superiores Acatlán, Universidad Nacional Autónoma de México. Becaria Conacyt, México. Correo electrónico: gracecarrazco@yahoo.com.mx

${ }^{1}$ Entrevista realizada en la Universidad de Salamanca, España, el 10 de junio de 2013.
} 
En esta entrevista nos habla de los motivos para estudiar élites políticas, de sus estudios continentales comparativos, de la metodología con la que trabaja, de los reconocimientos que ha recibido y de sus planes de investigación.

- ¿Por qué decidió estudiar élites políticas? ¿En qué momento surge ese interés?

- Surge hace justo veinte ańos al calor de la convicción de que las instituciones políticas son manejadas por hombres y mujeres -algo tan obvio como eso- y que la ciencia política prestaba poca atención al actuar de esos hombres y mujeres en la escena política. Entonces, la ciencia política se preocupaba fundamentalmente por las instituciones, por las reglas, como si las instituciones funcionaran autónomamente. Y entonces eso me llevó a pensar que sería interesante el estudio, en primer lugar, de los congresos, a través de las personas que trabajan en ellos y que los hacen posible, que son los diputados: ahí comenzó el proyecto de élites latinoamericanas. Pedimos un apoyo al Ministerio de Educación español y en 1994 me concedieron el primer proyecto; entonces, de una manera digamos, muy de ensayo y error, formulé un cuestionario para preguntar sobre la actividad política a los diputados y ahí me di cuenta, primero, que nadie había hecho eso, por lo menos en el ámbito latinoamericano, estaba un viejo, ¡vamos no tan viejo! trabajo de veinte años antes, de Putman, que lo había hecho con el parlamento inglés, el parlamento italiano y demás, seguidamente me di cuenta que tomando como unidad de análisis a los diputados -los diputados eran élites, claro, élites del sistema político- me podían dar mucha información para analizar otras cosas de la vida política. No sólo el parlamento, sino los propios partidos políticos y la propia democracia, el funcionamiento de la democracia. Y evidentemente esto estaba en las carreras de estas personas, ellos mismos como variantes dependientes del estudio. Ése fue el comienzo que, como siempre nos ocurre en la universidad, fue balbuciente, teniéndose que compaginar con las clases, con otro tipo de actividad; pero eso fue una constante en la que empezó a salir alguna pequeña investigación que terminó siendo la primera tesis doctoral y poco después el proyecto se fue expandiendo.

- ¿Y no ha sido difícil para usted hacer un estudio continental? O por lo menos del Cono Sur. 
- Continental. Sí, fue difícil pero por mi propia formación y el propio trabajo que he desempeñado en la Universidad española, siempre fui continental, es decir que, mi asignatura se llamaba "Sistemas Políticos de América Latina", el primer libro que hice se llamó así Sistemas Políticos de América Latina, invariablemente tuve una vocación de conocer el continente y con una visión comparada.

Continuamente el método comparado estuvo en mi trabajo y eso se trasladó eso al proyecto de élites parlamentarias. Irónicamente el primer proyecto que conseguí en 1994, se refería sólo en cuatro países, entre otras cosas por un problema de recursos económicos; estaban Argentina, México, Costa Rica y Ecuador, de esta forma había uno del Cono Sur, uno del norte, uno de Centroamérica y uno andino. Por eso inmediatamente me di cuenta que tenía que intentar conseguir fondos para ir ampliando el universo de estudio; siempre tuve el apoyo de estudiantes nuestros aquí en el doctorado, que son los que hacen el trabajo de campo, que consiste en entrevistas a diputados de forma personal e individualizada garantizando el anonimato, es decir, no es sólo entregar el cuestionario y volver al día siguiente para recogerlo, sino que las entrevistas se hacen cara a cara.

- ¿Cuál es su metodología más utilizada? ¿Trabaja cualitativa y cuantitativamente?

- En concreto este proyecto tuvo un componente claramente cuantitativo porque eran muestras representativas y luego los resultados de las encuestas se trataban estadísticamente; sin embargo, también recogía aspectos cualitativos, pero fundamentalmente el estudio es cuantitativo.

- ¿Y ahora es más cualitativo?

- Ahora es mitad y mitad. Creo que hay que combinar los dos métodos.

$-\succsim Y$ usted ha recibido premios, reconocimientos por este trabajo?

- Sí he recibido, en parte creo que los dos reconocimientos que he recibido, por los que estoy muy orgulloso son el doctorado Honoris Causa de la Universidad Nacional de San Martín, en Buenos Aires, y el Premio Bernardo O’Higgins, que 
concede el gobierno chileno, se deben a ello.

- ¿Y aquí en España lo han premiado?

- He recibido el premio María de Maeztu de mi Universidad a mi labor investigadora.

- Académicamente ¡cómo se siente a esta altura de su trayectoria?

- Bueno, yo diría que me siento muy frustrado porque hay muchas cosas por hacer, que no me da tiempo hacerlas, o que pienso que no tengo a lo mejor la energía suficiente para hacerlas, yo creo que, sin ir más lejos en este ámbito del estudio de los políticos, siento que sería fascinante entrar en el mundo de las élites provinciales o estatales, estaduales. Lo mismo que también sería fascinante entrar en el mundo de la élite local; pero, como digo, me interesan también las relaciones de estos individuos que se dedican a la política con otros ámbitos, la literatura, por ejemplo, me parece fascinante, la creación en general como dos grandes pulsiones del individuo que busca el poder por un lado, pero también el individuo que busca la vanidad del artista, que es una vanidad muy íntima. El artista crea, el político también crea, crea distribuyendo la riqueza o crea construyendo un partido político. Esa conexión me parece fascinante.

- Y también aspiran a que su nombre perdure, me parece...

- Sí, exacto, buscan la trascendencia. Por eso al político le encanta que le hagan una estatua o que le dediquen una calle. Es que la idea de la trascendencia es fundamental en el ser humano, todos queremos trascender ¿no?

- ¿Qué más sigue en su trabajo?

- Quiero también estudiar - porque me parece fascinante- todo lo que supone los nuevos conocimientos que estamos adquiriendo a través de los estudios sobre el cerebro en lo que se está viniendo en llamar neuropolítica, ¿por qué digo esto?, pues porque si mi unidad de análisis es un individuo que llamamos "político", a este individuo lo que le distingue y lo que le hace ser, precisamente, ser humano es 
tener un cerebro, tener una mente, razón, sentimientos y demás. Además, hoy por hoy, la neurología parece que es la disciplina que está avanzando más habiéndose destinado más fondos para investigar. Por consiguiente quiero entender el cerebro humano y en qué medida el cerebro puede ayudarnos a saber más; por ejemplo, a cerca de la ambición del político o de la propia idea de política, de cooperar con otros o de buscar una relación de reciprocidad y todo eso; no quiero tener una visión determinista, de pensar que eso lo va a explicar todo, pero sí me interesa entender el papel del cerebro.

- ¿Los proyectos académicos dependen mucho de los financiamientos que estén vinculados a ciertas áreas que, en determinados contextos, están en auge? ¿Eso ha determinado también su especialidad?

- Sí, lo que pasa es que, mucho más modestamente, yo he tenido la suerte de que en los últimos veinte años la economía española estuvo bien y han habido bastantes fondos para el estudio en el ámbito de las ciencias sociales, sin ningún tipo de cortapisa, ni ningún tipo de orientación; es decir, los planes nacionales de ciencia y tecnología aquí en España eran suficientemente generosos para presentar proyectos, en este caso innovadores, porque nadie los había hecho antes; proyectos que al fin y al cabo tuvieron, han tenido, y ahora mismo todavía sigo teniendo financiación pública. A lo que yo me refería antes también es que el 18 de febrero pasado, Barack Obama puso en marcha un plan de investigación soberbiamente dotado pata estudiar el mapa completo del cerebro humano. Los científicos esperan que la financiación sea de unos 250 millones de dólares al año con lo que van a contar en el mundo de la investigación de Estados Unidos. Entonces, agencias estatales, fundaciones privadas, equipos de neurocientíficos y nanocientíficos trabajarán juntos para descubrir el funcionamiento de los millones de neuronas que tiene el cerebro para tener una mirada más amplia de la apreciación, las acciones, y en última instancia, la conciencia. Esto, por supuesto, tiene mucho que ver para el estudio de Alzheimer, de Parkinson, etcétera, pero también en lo que yo estoy planteando, es decir, saber un poco más de por qué la gente hacemos política, de por qué alguien tiene la vocación de político, etcétera. Porque cuando hablamos del tema de vocación, cuando Eugen Bleuler habla de la vocación como impulso vital para hacer algo, bueno, esa vocación, se construye socialmente pero también hay un elemento biológico y eso me interesa. Entonces eso es a lo que 
yo me refería, me parece que un politólogo, o un cientista social, no puede ser ajeno a lo que se viene como consecuencia de esa inversión en ese ámbito. Y me parece que, lo mismo que se ha avanzado en el tema del genoma humano, que ha sido muy importante, yo creo que lo que va a pasar en Estados Unidos va a ser tremendamente relevante.

- Es muy interesante, pero ¿no es un salto mortal?

- Sí, hay que andar con cuidado para tampoco enloquecer y pensar que todo eso resuelve otro problema, pero creo que es un tema muy sugerente.

- ¿Cuál es la diferencia entre élites académicas y élites científicas?

- Es difícil establecer un límite. Claro, comunidad científica, comunidad académica, muchas veces se utilizan como sinónimos, yo mismo lo utilizo a veces como sinónimo. Parecería que la comunidad científica es algo más sólido que las comunidades académicas, porque las comunidades académicas, la academia es más, no digo que blando, pero no estoy seguro.

- ¿Las élites de las comunidades científicas tendrán que ver con las ciencias duras solamente?

- Parecería, claro; pero la diferencia es muy tenue porque para entender las ciencias duras me gusta mucho el trabajo de Mario Bunge, un gran filósofo argentino que trabaja sobre todo filosofía de la ciencia, es un hombre muy mayor, pero todavía, afortunadamente, vivo y muy activo. En Bunge hay, por una parte, la reivindicación de la importancia de lo empírico y de lo que puede ser validable, pero también hay ciertas gotas de escepticismo a propósito del alcance que pueda alcanzar, que pueda suponer el trabajo de las ciencias, de las ciencias de la naturaleza.

$\mathrm{Y}$ además es que puede haber científicos, estoy pensando, por ejemplo, en el caso español, un profesor de física que fue durante ocho años rector en la Universidad Autónoma de Madrid. Este profesor escribe habitualmente en $E l$ País, y a veces sus columnas son - pensando porque leí una columna de él hace una semana- de carácter científico-divulgativo pero otras son claramente políticas, son 
manifiestamente a favor de una determinada opción política a través de la opinión. Además de eso, es un científico que se anima a ser rector de una universidad, entonces en el fondo es porque tiene vocación política.

- ¿Cuál es el objetivo de las élites?

- Las élites se definen como grupos minoritarios que ocupan espacios de dirigencia, en ese sentido su objetivo es el poder, el poder que otorga el dinero por supuesto, pero también el poder de la inteligencia, incluso de la reputación.

- ¿Y usted estudiaría a otro tipo de élites aparte de las políticas?

- Estoy empezando a estudiar a cierto tipo de escritores, me interesan en relación con la política. Sobre políticos y escritores estoy escribiendo ahora. 